\title{
A reel-down instrument system for profile measurements of water vapor, temperature, clouds, and aerosol beneath constant-altitude scientific balloons
}

\author{
Lars E. Kalnajs ${ }^{1}$, Sean M. Davis ${ }^{2}$, J. Douglas Goetz ${ }^{1}$, Terry Deshler ${ }^{1}$, Sergey Khaykin ${ }^{3}$, Alex St. Clair ${ }^{1}$, \\ Albert Hertzog ${ }^{4}$, Jerome Bordereau ${ }^{5}$, and Alexey Lykov ${ }^{6}$ \\ ${ }^{1}$ Laboratory for Atmospheric and Space Physics, University of Colorado at Boulder, Boulder, Colorado 80303, USA \\ ${ }^{2}$ NOAA Chemical Sciences Laboratory, Boulder, Colorado 80305, USA \\ ${ }^{3}$ LATMOS/IPSL, UVSQ, Sorbonne Université, CNRS, Guyancourt, 78280, France \\ ${ }^{4}$ Laboratoire de météorologie dynamique, Sorbonne Université, Palaiseau, 91128, France \\ ${ }^{5}$ Laboratoire de météorologie dynamique, CNRS, Palaiseau, 91128, France \\ ${ }^{6}$ Central Aerological Observatory of Roshydromet, Dolgoprudny, 141700 Moscow Region, Russia
}

Correspondence: Lars E. Kalnajs (kalnajs@ colorado.edu)

Received: 29 August 2020 - Discussion started: 27 October 2020

Revised: 9 February 2021 - Accepted: 23 February 2021 - Published: 6 April 2021

\begin{abstract}
The tropical tropopause layer (TTL; 14-18.5 km) is the gateway for most air entering the stratosphere, and therefore processes within this layer have an outsized influence in determining global stratospheric ozone and water vapor concentrations. Despite the importance of this layer there are few in situ measurements with the necessary detail to resolve the fine-scale processes within this region. Here, we introduce a novel platform for high-resolution in situ profiling that lowers and retracts a suspended instrument package beneath drifting long-duration balloons in the tropics. During a $100 \mathrm{~d}$ circumtropical flight, the instrument collected over a hundred $2 \mathrm{~km}$ profiles of temperature, water vapor, and aerosol at $1 \mathrm{~m}$ resolution, yielding unprecedented geographic sampling and vertical resolution. The instrument system integrates proven sensors for water vapor, temperature, pressure, and cloud and aerosol particles with an innovative mechanical reeling and control system. A technical evaluation of the system performance demonstrated the feasibility of this new measurement platform for future missions with minor modifications. Six instruments planned for two upcoming field campaigns are expected to provide over 4000 profiles through the TTL, quadrupling the number of high-resolution aircraft and balloon profiles collected to date. These and future measurements will provide the necessary resolution to diagnose the importance of competing mechanisms for the transport of water vapor across the TTL.
\end{abstract}

\section{Introduction}

Super-pressure balloons are emerging as a practical platform for Earth science observations at altitudes from the upper troposphere to the mid-stratosphere, carrying payloads ranging from a few up to thousands of kilograms with durations ranging from weeks to close to a year. The balloons, drifting on an isopycnic surface, provide measurements along a quasiLagrangian trajectory.

The Reeldown Aerosol Cloud Humidity and Temperature Sensor (RACHuTS) is an instrument system developed to perform profile measurements of the atmosphere up to $2 \mathrm{~km}$ below a super-pressure balloon (Fig. 1). The instrument system consists of three primary assemblies: a reeling system that is contained within the primary balloon gondola, a smaller sub-gondola or profiler that is lowered from the primary gondola, and a suite of sensors within the profiler that measure position, temperature, pressure, water vapor, and aerosol and cloud particles. The RACHuTS instrument was specifically designed for the Stratéole 2 field experiment - a series of long-duration ballooning campaigns to study the tropical tropopause layer (TTL) using a constellation of super-pressure balloons circling the Earth at the Equator (Haase et al., 2018). The Stratéole 2 experiment is comprised of three field missions: a recently completed engineering test campaign (November 2019-March 2020) with 
eight balloons, the first science campaign in 2021 with 20 balloons, and a second science campaign in 2024 in the opposite phase of the Quasi Biennial Oscillation (QBO), also with 20 balloons. A total of seven RACHuTS instruments will be deployed during the experiment; one was deployed during the engineering test campaign, and three will be deployed on each of the upcoming science campaigns. This work describes the RACHuTS instrument design and operation, the technical performance of the overall instrument system during the Stratéole 2 engineering test campaign, and the scientific performance of the sensors within the profiler.

\subsection{Background}

The Stratéole 2 mission builds on the technical accomplishments of three long-duration super-pressure balloon campaigns in the Antarctic and tropical lower stratosphere. The Vorcore experiment, in 2005, flew 27 super-pressure balloons from McMurdo Station, Antarctica, at altitudes between 17.5 and $19.5 \mathrm{~km}$ (Hertzog et al., 2007). The Concordiasi campaign in 2010 flew 19 super-pressure balloons from McMurdo Station carrying more extensive instrument payloads than used during Vorcore (Boullot et al., 2016; Hoffmann et al., 2017; Rabier et al., 2012). As part of the preparations for the Concordiasi campaign, three engineering test flights were conducted from the Seychelles during the pre-Concordiasi campaign (Podglajen et al., 2014). Stratospheric winds near the Equator are primarily zonal, with the direction determined by the altitude and the phase of the QBO; thus balloons released into the tropical lower stratosphere will tend to circumnavigate the tropics (Baldwin et al., 2001). PreConcordiasi validated the concept of flying super-pressure balloons in the tropics; each of the three balloons flew for longer than 3 months, with one making a circumnavigation of the globe, while the other two balloons reversed course as the phase of the QBO reversed. These engineering flights served as the pathfinder for a dedicated equatorial balloon experiment, Stratéole 2, with a focus on observing the TTL.

The TTL is a region of particular scientific interest, but it also suffers from a scarcity of scientific observations. In contrast to the abrupt transition from the troposphere to stratosphere that is typical of the midlatitude tropopause, the tropical tropopause layer is a $4 \mathrm{~km}$ thick transition region, having properties of both the troposphere and stratosphere (Fueglistaler et al., 2009). The TTL forms a gateway to the stratosphere, as most of the air that enters the global stratosphere passes through the TTL; thus the TTL strongly impacts the composition of the global stratosphere. The microphysics, thermodynamics, and dynamics of the TTL are complex and inhomogeneous, driven by powerful tropical convection that impacts the TTL through detrainment, mixing, and wave disturbances. While of great scientific importance, processes in the TTL are difficult to observe, leading to a scarcity of detailed measurements. The altitude of the TTL, $14-18.5 \mathrm{~km}$, is above the flight ceiling for most research air- craft, with only a handful of aircraft experiments focusing on this region (Jensen et al., 2015; Krämer et al., 2020). The region is a thin, cold, and dry layer on top of the thick, warm, and wet tropical troposphere, making it difficult to observe from satellites. Many of the processes within the TTL occur at fine vertical scales, much smaller than is resolvable by spaceborne sensors (Randel and Jensen, 2013). Finally, many of the countries in the equatorial belt are developing nations, with few resources to allocate to making regular balloonborne soundings of the TTL. As a result, there is only a single tropical site performing routine water vapor soundings from Costa Rica (Selkirk et al., 2010), a few campaign measurements over South America and the oceans (Fujiwara et al., 2010; Hasebe et al., 2013; Suzuki et al., 2013), and no measurements over equatorial Africa.

The Stratéole 2 experiment is designed to overcome many of these limitations by making high-resolution in situ and remote-sensing measurements of the TTL from a constellation of super-pressure balloons circumnavigating the tropics. The Stratéole 2 balloon platform consists of 11 and $13 \mathrm{~m}$ diameter super-pressure balloons each carrying two gondolas. The upper gondola (the "Euros"), manufactured and operated by the Centre National d'Etudes Spatiales (CNES), carries the flight control and flight safety equipment. For safety reasons the Euros is completely isolated from the lower gondola (the "Zephyr"), designed and operated by the Laboratoire Atmosphères, Milieux, Observations Spatiales (LATMOS), the Laboratoire de Météorologie Dynamique (LMD), and Division Technique de l'INSU (DT-INSU), which hosts the scientific instruments. Each Zephyr can host two to three instruments, with a total instrument mass of $8 \mathrm{~kg}$ and a total average power consumption of $10 \mathrm{~W}$. The Zephyr provides the infrastructure to host the instruments, including batteries, solar energy system, thermal regulation, and bi-directional communications, through an Iridium satellite link. The Stratéole 2 balloons fly at two density levels. The $11 \mathrm{~m}$ balloons fly at a density level of $125 \mathrm{~g} \mathrm{~m}^{-3}$, or approximately $18.5 \mathrm{~km}$, and are targeted at in situ observations at the top edge of the TTL. The $13 \mathrm{~m}$ balloons fly at a density level of $100 \mathrm{~g} \mathrm{~m}^{-3}$, or approximately $20.5 \mathrm{~km}$, in the lower stratosphere and primarily host remote-sensing instruments. The balloons are expected to fly for $90-120 \mathrm{~d}$ and will circumnavigate the globe within a flight domain of $20^{\circ} \mathrm{S}$ to $15^{\circ} \mathrm{N}$.

Given that Stratéole 2 balloons are designed to maintain neutral buoyancy, in situ measurements are limited to a single density level. RACHuTS is designed to overcome this restriction by probing the atmosphere down to $2 \mathrm{~km}$ below the flight level of the balloon. Deployment of a reel-down sub-gondola from a balloon in flight is complex both from a technical and regulatory stand point. There are few previous examples of this technology in the literature, and prior work is limited to systems that were not deployed on an operational basis. Hazen and Anderson (1985) describe a large winch system that was deployed on a zero-pressure balloon on at least two occasions, deploying a $62 \mathrm{~kg}$ payload $12 \mathrm{~km}$ below a drift- 


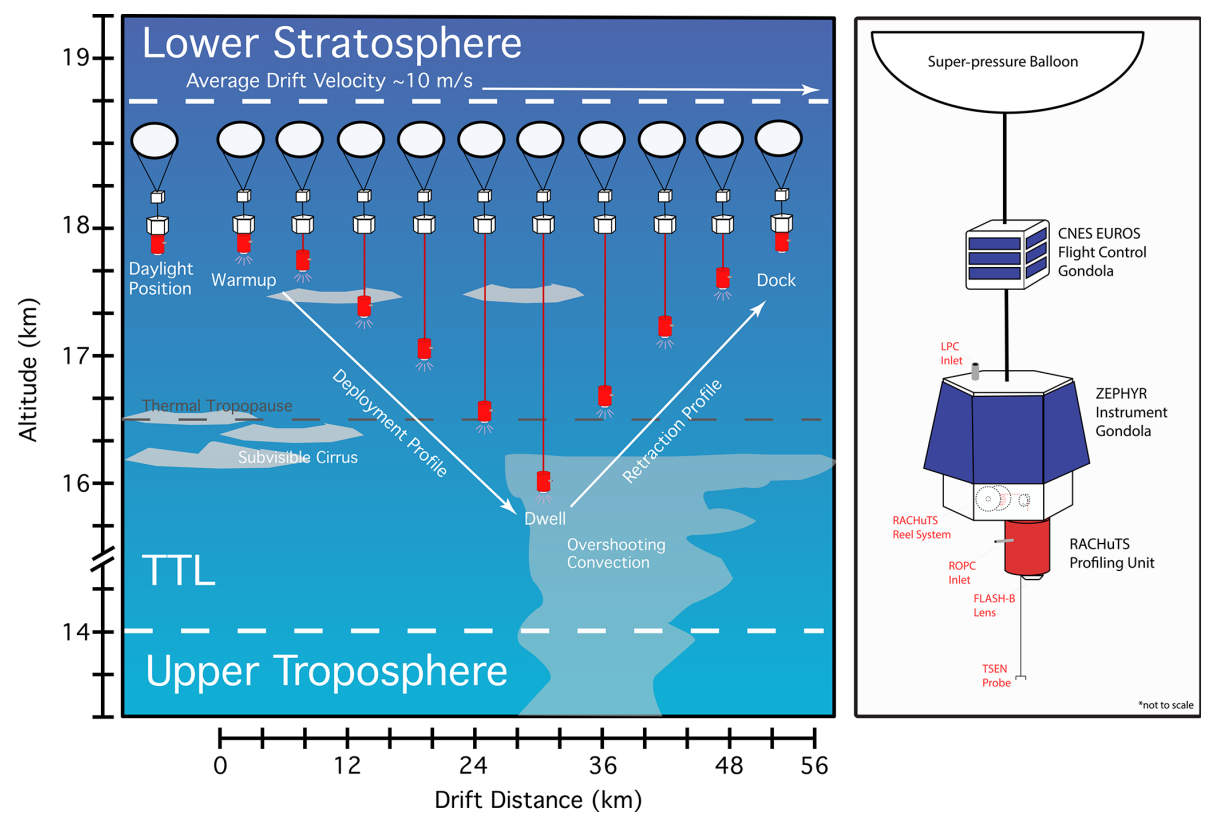

Figure 1. RACHuTS operational concept. The RACHuTS profiler is deployed from a super-pressure balloon at $18.5 \mathrm{~km}$, down to an altitude of $16.5 \mathrm{~km}, 3-5$ times per night making measurements of water vapor, aerosol, cloud particles, temperature, and pressure.

ing zero-pressure balloon at an altitude of $39 \mathrm{~km}$ over Palestine, Texas. At about the same time, a smaller winch system was developed in Japan to deploy a $22 \mathrm{~kg}$ payload $3 \mathrm{~km}$ below a zero-pressure balloon in flight (Matsuzaka et al., 1985). Miniaturized instruments, advanced manufacturing and materials, and improvements in battery technology have made smaller, lighter, and less expensive reel-down systems a reality for use on constellations of small balloons without the prospect of instrument recovery.

\subsection{Design criteria}

The design of the RACHuTS instrument is a compromise between science requirements, logistical constraints of the Zephyr, regulatory requirements for international air space, and safety requirements from the balloon operator, CNES, to insure the survival and safe operation of the balloon system. The primary scientific requirements are high vertical resolution, sufficient measurement sensitivity for the lower stratosphere, and a vertical extent to cover as much of the TTL as possible, including spanning the cold-point tropopause. The Zephyr has limited resources for allowable mass, power, data, and thermal control. RACHuTS shares a Zephyr with the Laboratory for Atmospheric and Space Physics (LASP) particle counter (LPC), leaving RACHuTS a mass budget of $6 \mathrm{~kg}$, daily average power of $5 \mathrm{~W}$, and daily data downlink budget of $1.2 \mathrm{MB}$.

The International Civil Aviation Organization (ICAO), maintains the Convention on International Civil Aviation, which includes internationally adopted Rules of the Air (Annex 2) governing the operation of aircraft (ICAO, 2005). The
Rules of the Air govern the operation of "unmanned free balloons" in international airspace. There are negligible regulations for the operation of an unmanned balloon above an altitude of $\sim 18 \mathrm{~km}$ (FL 600), where the main Stratéole 2 balloons fly. However, while the Zephyr will remain above $18 \mathrm{~km}$, the profiler will descend to $16 \mathrm{~km}$, where it is subject to more stringent regulation. There is an exemption to many of these regulations for lightweight balloon payloads such as radiosondes. Thus, by meeting the standards for a lightweight instrument, the profiler is exempt from most restrictions below $18 \mathrm{~km}$. These standards applied to the profiler restrict the mass to less than $3 \mathrm{~kg}$ and the fiber, suspending the profiler, to break at an impact force of $230 \mathrm{~N}$.

The deployment of the sub-gondola from the main gondola during flight has consequences for the operation and safety of the overall balloon system that impose further requirements. The two primary concerns are (i) accidental loss of the profiler and (ii) drag or lift generated by the profiler from wind shear encountered during a profile. Loss of the profiler has the potential to be catastrophic, forcing the balloon to lower ambient pressures and hence to a super-pressure environment exceeding the balloon design strength. A similar situation could occur if the deployed profiler encountered significant wind shear. Counterintuitively, wind shear on a tensioned line will cause lift (Alexander and Stevenson, 2001), reducing the load on the balloon leading to additional balloon overpressure. These concerns led to the following instrument requirements. The profiler must withstand the highest loads expected during flight, typically at launch or flight termination, estimated at 13 times gravity $(g)$, without loss of the profiler, and the mechanical reeling system must be incapable 
of breaking the line. Finally, the deployment of the profiler initially will be phased and occur in coordination with the flight dynamics managers to allow for the impacts on balloon overpressure to be assessed.

\section{Instrument description}

RACHuTS consists of three main subsystems: the reeling system, the profiler gondola, and the profiler sensor suite, consisting of a temperature and pressure sensor (TSEN, Thermodynamical SENsor), water vapor sensor (FLASH-B, Fluorescence Lyman-Alpha Stratospheric Hygrometer), and cloud and aerosol sensor (ROPC, RACHuTS optical particle counter).

\subsection{Reeling system}

The reeling system is contained within the Zephyr, and consists of the mechanical assembly to unspool and spool the profiler line, the electro-mechanical interface to the profiler, and the electrical control and communications interface to the Zephyr (Fig. 2). The core of the reel system is a $6 \mathrm{~cm}$ diameter by $12 \mathrm{~cm}$ long spool (Fig. 2b, yellow), which is 3-D printed using selectively laser-sintered (SLS) carbon fiber reinforced nylon. The spool is designed to accommodate up to $3 \mathrm{~km}$ of line, but was loaded with $2.2 \mathrm{~km}$ for the Stratéole 2 engineering campaign. The spool is driven by the primary drivetrain using a brushless DC servomotor and planetary gear box (Fig. 2 a, red) providing $2.4 \mathrm{Nm}$ of peak torque at speeds up to 650 revolutions $\min -1$. This translates to a maximum pulling force of $60 \mathrm{~N}$ with an empty spool, well below the minimum breaking strain of the line and approximately 3 times higher than the nominal gravitational load of $22 \mathrm{~N}$ from the $2 \mathrm{~kg}$ profiler and line. An electromagnetic friction brake provides $4.8 \mathrm{~N} \mathrm{~m}$ of holding force to the reel. The electromagnetic brake is failsafe; a current must be applied to release the brake and in the event of a loss of power the brake will engage, holding the profiler. A secondary drive (Fig. 2d, blue) is digitally slaved to the primary drive and powers a level wind carriage (Fig. 2c, green), which oscillates back and forth across the width of the reel, evenly distributing the line on the reel.

The profiler is suspended by a $280 \mu \mathrm{m}$ diameter ultrahigh molecular-weight polyethylene (UHMWPE, trade name Spectra) braided line with a weight of $200 \mathrm{~g} \mathrm{~km}^{-1}$. Multiple sections of line were pull-tested to failure with a mean breaking strain of $192 \mathrm{~N}$ at $25^{\circ} \mathrm{C}(\mathrm{SD} 5.7 \mathrm{~N})$. One property of particular importance to the measurement environment is the glass transition temperature of UHMWPE and the temperature-dependent breaking strain, as the line will be passing through the cold point at temperatures as low as $-90^{\circ} \mathrm{C}$. The glass transition temperature $-150{ }^{\circ} \mathrm{C}$ is well below the lowest temperatures expected (Sobieraj and Rimnac, 2009), and pull testing was repeated in a thermal chamber,

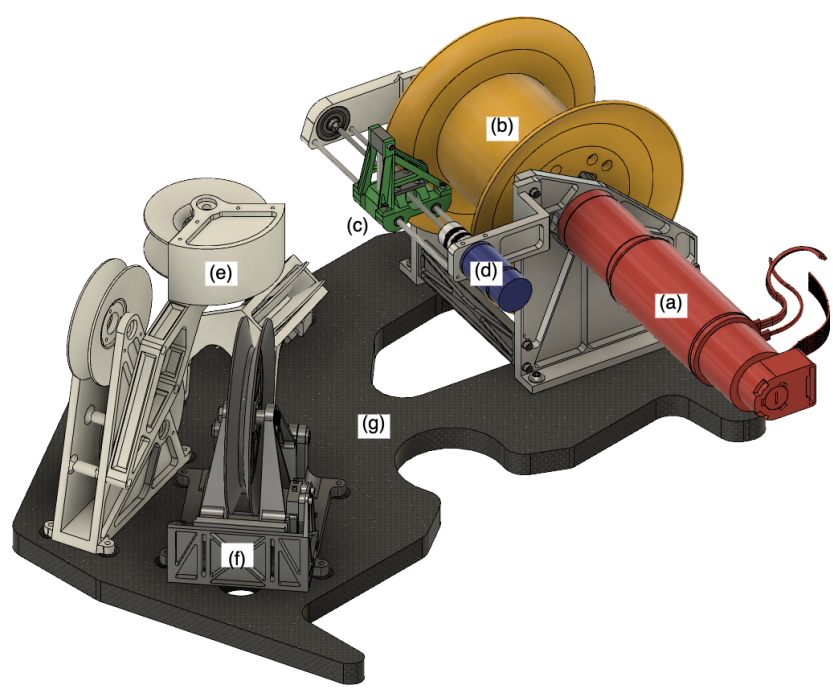

Figure 2. Rendering of the RACHuTS reel system. Major assemblies include the primary drivetrain (a, red), reel (b, yellow), level wind carriage (c, green), level wind motor (d, blue), line redirection pulley train (e, white), kinematic pulley (f, grey), and carbon fiber baseplate (g, black twill). The line, electronics box, and docking connector are not shown. The line is routed from the reel, through the level wind, around the redirection pulleys to align with the kinematic pulley, exiting the gondola through the hole in the baseplate (near f).

with a maximum yield strength of $204 \mathrm{~N}$ reached at $-80^{\circ} \mathrm{C}$. This is below the ICAO mandated $230 \mathrm{~N}$ breaking strain but a factor of 10 above the nominal load from the profiler. To meet the flight safety requirement of withstanding a $13 \mathrm{~g}$ acceleration (a $260 \mathrm{~N}$ force on the line) the first $5 \mathrm{~m}$ of the line were reinforced with a supplemental $1.2 \mathrm{~mm}$ diameter UHMWPE braid with a tensile strength in excess of $1 \mathrm{kN}$, jacketing the primary line. The braided line enters the bottom of the Zephyr through the profiler docking connector. From there, the line passes over a large-diameter springloaded pulley (Fig. 2f, grey). This kinematic pulley serves two purposes: it provides a mechanism to dissipate shock, as the UHMWPE has a high elastic modulus (low stretch), and it provides over- and underload detection. The pulley is spring loaded in two directions; under a high-load situation the pulley moves toward the exit orifice, actuating an overload microswitch. If the system becomes unloaded, risking tangling in the line, the pulley moves away from the exit orifice tripping a second underload microswitch. The line and motor systems were subject to extensive lifetime testing in the laboratory. Using two RACHuTS reel systems on opposite ends of $2 \mathrm{~km}$ of line, over 600 profiles were simulated by deploying the line from one reel, while reeling it onto the other reel and then reversing the process.

On the exterior of the bottom of the Zephyr is the profiler docking connector. This unit provides both a mechanical guide to steer the profiler into alignment with the Zephyr as 
well as electrical connection to the profiler. Four gold rings on the bottom of the Zephyr contact four concentric rings of spring-loaded contact pins on the top of the profiler, providing power and communications with the profiler while docked.

The reel system is controlled by an ARM Cortex microcontroller on the purpose-built motion control board (MCB). The MCB enforces programmable limits on speeds, torques, currents, and voltages to the motors while collecting performance data for each profile. The interface between the MCB, the profiler, and the Zephyr is provided by a second module, the profiler interface board (PIB), also purpose-built around an ARM Cortex microcontroller. The PIB initiates a profile by sending commands to the docked profiler to begin making measurements and then commanding the MCB to begin reeling operations. At the completion of a profile the PIB offloads the stored science data from the profiler, collects the reel performance data from the MCB, and then sends the compressed data on to the Zephyr for transmission to the ground station.

\subsection{Profiler}

The profiler, lowered from the Zephyr, obtains power and communications from the Zephyr (through the PIB and docking connector) while docked. Figure 3 is a rendering of the profiler comprised of FLASH-B (Fig. 3a, blue), TSEN electronics (Fig. 3b, yellow), ROPC (Fig. 3c, black and green), and rechargeable batteries (Fig. 3d, red) . The profiler is housed in a $25 \mathrm{~cm}$ diameter by $28 \mathrm{~cm}$ tall expanded polystyrene (EPS) cylindrical thermal housing with an overall weight of $1.8 \mathrm{~kg}$. As the profiler is outside the Zephyr, thermal management is controlled internally.

Control and data storage for the profiler are provided by an ARM Cortex microcontroller, which interfaces with each of the sensors via a serial connection and with the PIB when docked. The control board also includes a temperature measurement system for temperature control and engineering data, two temperature control loops, a GPS receiver, and a flash memory card for data storage. Power for the profiler is provided by a lithium-ion battery pack, with sufficient capacity for five profiles and $24 \mathrm{~h}$ of thermal management. The battery pack is charged from the Zephyr while docked. Lithium batteries can be damaged through lithium plating when charged at temperature below $0{ }^{\circ} \mathrm{C}$ (Petzl et al., 2015); thus the battery pack is temperature controlled at $0^{\circ} \mathrm{C}$, while the rest of the profiler is controlled to $-20^{\circ} \mathrm{C}$.

\subsubsection{TSEN temperature and pressure sensor}

Temperature and pressure measurements on the profiler are made using the Thermodynamical SENsor (TSEN) instrument, developed and supplied by LMD in Paris, France (Hertzog et al., 2007). The instrument measures ambient air temperature outside the profiler gondola with a smalldiameter silver-coated thermistor suspended on a wire $5 \mathrm{~m}$

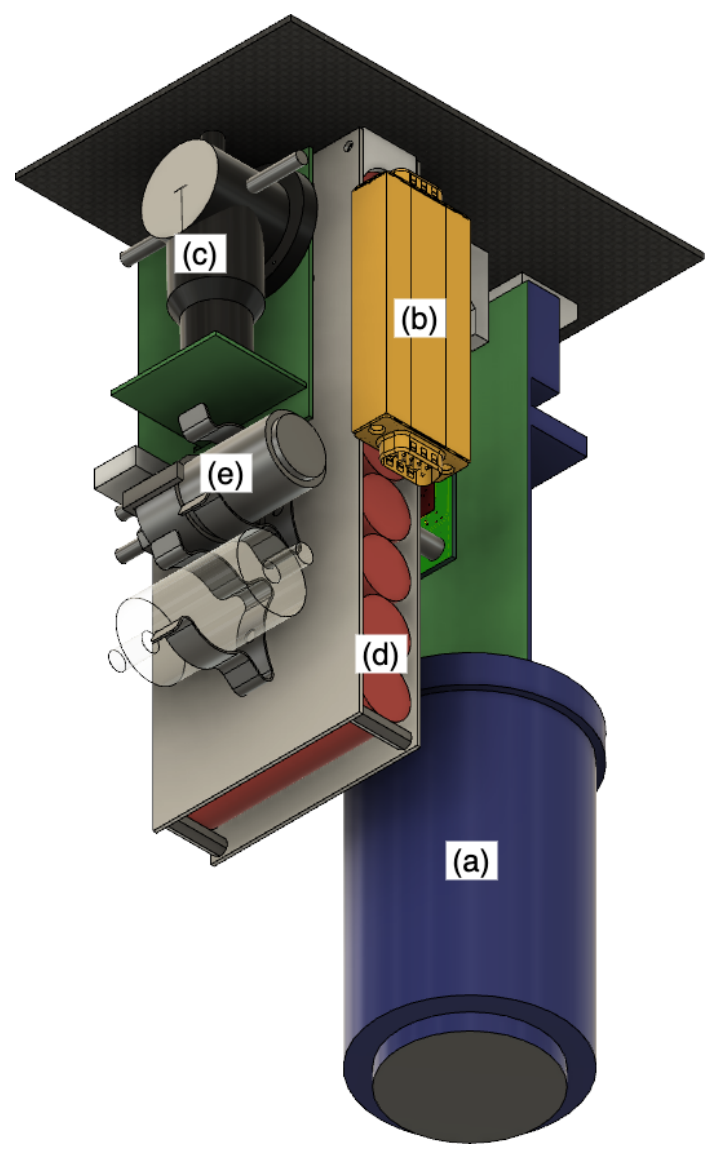

Figure 3. Rendering of RACHuTS profiler. The FLASH-B water vapor sensor (a, blue), TSEN pressure sensor and electronics (b, yellow), and ROPC aerosol and cloud particle detector (c, black and green) are visible. Other components include the lithium-ion battery pack (d, red) and the ROPC pump (e, silver). The TSEN temperature sensor and main control board are not visible. The thermal housing and docking connector are omitted for clarity.

below the profiler. Pressure is measured inside the profiler using a board-mounted silicon pressure sensor, with an integrated analog-to-digital converter. The temperature of the pressure sensor is measured internally to provide a temperature-compensated pressure measurement. The TSEN electronics are housed in the temperature-controlled environment inside the profiler and report pressure and temperature at $1 \mathrm{~Hz}$ both during the profiles and at flight level.

TSEN has a long flight heritage on super-pressure stratospheric balloons and is well characterized in the lowermost stratosphere. Prior generations of the TSEN instrument were deployed on multiple super-pressure balloons in a similar configuration during the Vorcore campaign in Antarctica in 2005 (Hertzog et al., 2007), on the Concordiasi campaign in Antarctica in 2010 (Ward et al., 2014; Hoffmann et al., 2017), and in the tropics during pre-Concordiasi also in 2010. The version of TSEN used in the profiler is slightly evolved from the Concordiasi instrument with an improved thermis- 
tor with a reduced size to decrease solar bias. Furthermore, the TSEN in the profiler uses the much smaller and lighter MS5803 pressure sensor instead of the larger quartz crystal barometers used in the standard TSEN.

The TSEN temperature sensor accuracy and precision, determined during prior flight campaigns, are $0.1 \mathrm{~K}$ at night and $0.25 \mathrm{~K}$ during the day when corrected for solar radiation (Hertzog et al., 2004). For the RACHuTS profiles a precision of $0.1 \mathrm{~K}$ can be assumed as the profiles are collected at night, and the sensor is ventilated by the vertical motion of the profiler and any horizontal wind shear. The pressure sensor is specified by the manufacturer to have an absolute accuracy of $\pm 2 \mathrm{hPa}$ and a precision of $0.01 \mathrm{hPa}$ over the temperature range inside the profiler. A higher absolute accuracy can be obtained by performing cross-calibration with the TSEN in the Euros gondola while the profiler is docked.

\subsubsection{FLASH-B water vapor sensor}

FLASH-B is a compact and lightweight version of the FLASH (Fluorescence Lyman-Alpha Stratospheric Hygrometer) instrument developed at the Central Aerological Observatory in Russia specifically for balloon-borne measurements of water vapor in the upper troposphere and lower stratosphere (Yushkov et al., 1998). The instrument senses water vapor by measuring the intensity of fluorescence from $\mathrm{OH}$ radicals that have been photodissociated from water molecules exposed to Lyman-alpha radiation $(121.6 \mathrm{~nm})$. The Lyman-alpha is produced by an onboard hydrogen lamp, whereas the fluorescence signal at $308-316 \mathrm{~nm}$ is measured using a photomultiplier tube in photon-counting mode. The intensity of the fluorescence is directly proportional to the water vapor mixing ratio at stratospheric conditions (Yushkov et al., 1998). FLASH-B uses a coaxial open-path optical layout, in which the measurement volume is located outside the instruments, $2-3 \mathrm{~cm}$ away from the lens of the instrument. To reduce the background light and to avoid saturation of the photomultiplier tube, FLASH-B can only be operated at night; thus RACHuTS profiles are only collected with a solar zenith angle (SZA) greater than $95^{\circ}$. FLASH$\mathrm{B}$ is installed within the profiler housing with the lens facing downward. Since the lens assembly, exposed to ambient temperature at one end, provides a thermally conductive path for heat loss, FLASH-B is thermally isolated from the other profiler components by an $8 \mathrm{~mm}$ thick aerogel blanket and provides its own thermal management, regulating to $-20^{\circ} \mathrm{C}$ during operation.

FLASH-B has a significant flight heritage on sounding balloons in the tropics (Khaykin et al., 2009) and in the Arctic (Khaykin et al., 2013), as well as in a previous longduration balloon experiment (Lykov et al., 2014). The performance of FLASH-B has been extensively documented both in laboratory intercomparisons (Fahey et al., 2014) and through collocated balloon soundings with frost-point, tunable diode laser, and Lyman-alpha hygrometers (Ghysels et al., 2016; Khaykin et al., 2013; Vömel et al., 2007), yielding mean relative deviations of less than $2.4 \%$ in the lower stratosphere.

Prior to delivery, the FLASH-B instrument is calibrated in a stratospheric simulation chamber at constant pressure $(50 \mathrm{hPa})$ and temperature $\left(-40^{\circ} \mathrm{C}\right)$ over a wide range of mixing ratios (1-100 ppmv) against the reference dew point hygrometer MBW 373L. The detection limit for a $4 \mathrm{~s}$ integration time is of the order of $0.1 \mathrm{ppmv}$, while the accuracy is limited by the calibration error amounting to $4 \%$. The typical precision in the stratosphere is $5 \%-6 \%$, whereas the total uncertainty is less than $10 \%$ throughout the stratosphere. During profiles, the primary measurement data (i.e., the fluorescence signal) is reported and stored at $1 \mathrm{~Hz}$, whereas housekeeping and diagnostic data are reported at $0.1 \mathrm{~Hz}$.

\subsubsection{RACHuTS optical particle counter}

The RACHuTS optical particle counter (ROPC) is a small eight-channel OPC optical head based on the MetOne 9722-1 optical head. The ROPC is a closed-path instrument that uses a constant-volume rotary vane pump to draw $3.5 \mathrm{~L} \mathrm{~min}^{-1}$ of air in through a $3 \mathrm{~mm}$ diameter inlet tube and through a laser beam. Particles in the airstream scatter light from the $670 \mathrm{~nm}$ laser diode. The side-scattered light is collected over a cone from $60-120^{\circ}$ with an elliptical mirror which focuses the scattered light pulses on a photodiode. The electrical signal from the photodiode is digitized and the intensity of each pulse is divided and accumulated into eight bins by a pulse height analyzer, representing eight size bins approximately logarithmically spaced from $0.3-10 \mu \mathrm{m}$ diameter. The rotary vane pump is a constant-volume pump and thus pulse frequency is easily converted to aerosol concentration. After passing through the pump, the air passes through a $0.01 \mu \mathrm{m}$ filter to remove particles generated by the graphite vanes in the pump, before being exhausted to the atmosphere. The first size bin, $0.3 \mu \mathrm{m}$, is recorded at $1 \mathrm{~Hz}$, while the larger channels have an $8 \mathrm{~s}$ integration time.

The ROPC has a less extensive stratospheric heritage than the either TSEN or FLASH-B. A version of the MetOne 9722 optical head is used in the LASP stratospheric total aerosol counter (STAC - a balloon-borne condensation particle counter) and has been flown on sounding balloons numerous times over the past 3 years. Total aerosol concentration profiles from the STAC have agreed with similar profiles from the University of Wyoming condensation nuclei (CN) counter (Rosen and Hofmann, 1977; Campbell and Deshler, 2014) within geophysical variations of $\mathrm{CN}$ profiles. An inflight comparison was also made between the ROPC and the Wyoming laser particle counter (WLPC) (Ward et al., 2014) in 2018 on a sounding balloon. Below $20 \mathrm{~km}$ the instruments agreed to within $20 \%$; however, the ROPC detection efficiency decreased relative to the LPC above $20 \mathrm{~km}$. Unlike the STAC or WLPC, the ROPC does not use a filtered air sheath flow to constrain the sample air jet, and it is possible that at 
pressures below $50 \mathrm{hPa}$ the air jet through the laser beam begins to diverge, lowering the counting efficiency. While this effect is unlikely to impact the RACHuTS measurements that are all below $20 \mathrm{~km}$, the ROPC will require further validation. Furthermore, the orientation of the ROPC inlet in relation to the relative wind speed during profiles is unknown; thus the sampling efficiency of the inlet for larger particles is not well characterized. The ROPC was primarily included in the payload to detect super-micrometer cirrus cloud ice particles, while the measurement of the number density of ice particles needs further validation during flight; there is high confidence in the ability to detect cloud particle $(d>1 \mu \mathrm{m})$ at concentrations above $0.1 \mathrm{~L}^{-1}$ with limited quantitative confidence.

\section{Stratéole 2 engineering flight}

The first field activity of the Stratéole 2 experiment took place in October to December 2019 at the Seychelles International Airport on the island of Mahé in the Seychelles $\left(4.67^{\circ} \mathrm{S}, 55.52^{\circ} \mathrm{E}\right)$. This campaign was an engineering test and proof of concept for the two primary science campaigns scheduled to occur in 2021 and 2024. During the campaign, one of each balloon configuration was flown, with some additional tests for a total of eight balloon flights. RACHuTS was hosted on the "TTL3" configuration of the Zephyr, sharing the gondola with an LPC and using an $11 \mathrm{~m}$ diameter super-pressure balloon. The TTL3 flight was launched at 19:20 UT on 18 November and reached a stable float altitude of $18.8 \mathrm{~km}$ the following day. The flight lasted $101 \mathrm{~d}$ and was terminated on 28 February 2020 off the east coast of Ecuador $\left(3.33^{\circ} \mathrm{S}, 81.42^{\circ} \mathrm{W}\right)$ after completing 1.5 circumnavigations of the Earth (Fig. 4).

Due to calm winds at launch, necessitating the rapid movement of the gondola, the release of the Zephyr was more dynamic than planned, leading to minor damage to the RACHuTS docking connector. The profiler oscillated below the gondola as the launch team had to both hold the gondola high and pivot the balloon, ascending over the release point, towards them. As a result of this damage, and from possible ice build-up on the connector during ascent through dense clouds, multiple manual tele-commands (TCs) and redocking procedures were required to re-establish communications with the profiler unit. Communications were reestablished on 21 November, and instrument commissioning began with phased manual profiles. No negative consequences were observed for the dynamics of the balloon system, and the first full $2 \mathrm{~km}$ long science profile was performed on 23 November.

The instrument operational plan specified switching to an automatic profiling mode soon after commissioning. In automatic mode, RACHuTS would autonomously begin profiling when the SZA surpassed $95^{\circ}$. To begin a profile, the profiler requests permission from the Zephyr to commence profiling.
Once granted, the profiler enters warmup mode, nominally 15 min with all the instruments in the profiler running. Once warmup is complete, the reel deploys 7500 revolutions, lowering the profiler $2 \mathrm{~km}$ below the Zephyr at a vertical speed of $-1 \mathrm{~m} \mathrm{~s}^{-1}$. At the completion of the reel-out, the instrument enters a $15 \mathrm{~min}$ dwell period at the bottom of the profile, and the reel performance data from the MCB are telemetered to the ground. The profiler is then retracted $1.95 \mathrm{~km}$ at $1 \mathrm{~m} \mathrm{~s}^{-1}$. The final $50 \mathrm{~m}$ approach to the gondola is performed at $0.1 \mathrm{~m} \mathrm{~s}^{-1}$, until the torque feedback indicates the profiler is docked. At this point the profiler offloads the approximately $200 \mathrm{kB}$ of profiler data to the Zephyr, which sends them to the ground along with the reel performance data from the ascent. Once data offload is complete, power to the profiler is turned off and the battery is recharged for the next profile or for entering a daytime hibernate or charge mode if the $\mathrm{SZA}<115^{\circ}$.

The mission specification for the RACHuTS flights is three to four cycles per night, yielding six to eight profiles through the TTL as data are collected both on descent and ascent. Unfortunately, due to the intermittent communications through the docking connector and a compounding software error, all the cycles during the engineering flight were commanded manually using TCs from the ground. Fifty-five full cycles were completed over the course of the flight, yielding 110 profiles through the TTL and meeting the goals of the engineering campaign by demonstrating the instrument functionality and assessing the performance of the measurements. Had the profiler operated nominally in automatic collection mode, there would have been 300-400 full cycles.

\subsection{Reel system performance}

As an entirely new and complex system, validating the performance of the RACHuTS reeling system was one of the primary goals of the engineering test flight. Motor performance data for all one hundred and ten $2 \mathrm{~km}$ motions were consistent with pre-flight engineering analysis and laboratory tests. During the ascent portion of each cycle, reel power consumption averaged $39 \mathrm{~W}$ with a motor current of $2.6 \mathrm{~A}$ at a nominal voltage of $15 \mathrm{~V}$. During the descent phase of each cycle the reel motor acts as a retarder, counteracting the gravitational acceleration on the profiler and generating net counterelectromotive force. This generated power was shunted to a large power resistor on the electronics box housing to be dissipated as heat and to limit the increase in motor voltage. A possible concern identified before the flight was the ability to dissipate this heat in the low-pressure stratospheric environment; however the reverse current flow in flight was lower than expected $(\sim 0.1 \mathrm{~A})$ and did not negatively impact ambient temperature within the gondola.

The motor diagnostics, including motor current and temperature, were used as indicators of reel system degradation over the course of the engineering flight. Deterioration of the motors, bearings, or pulley train would appear as an increase 


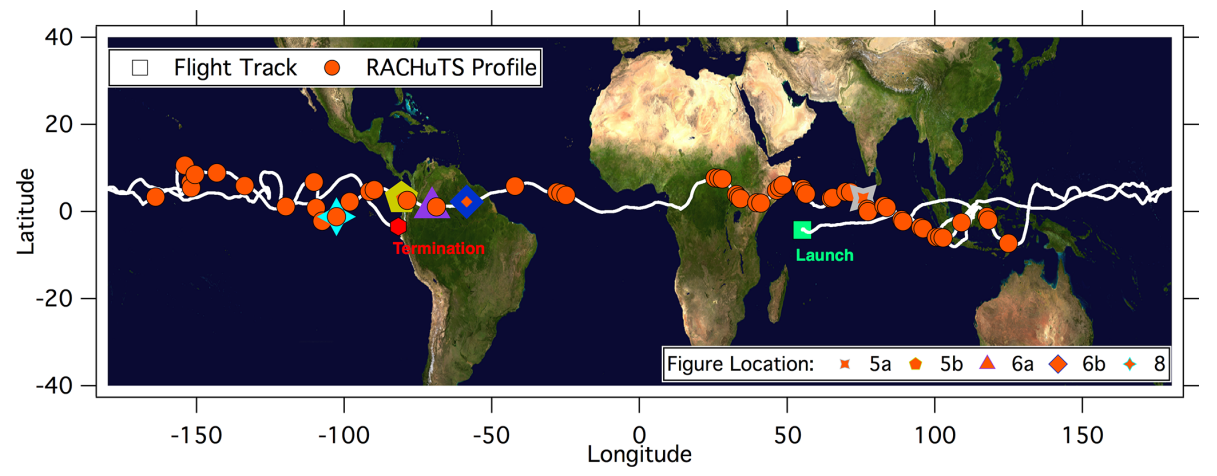

Figure 4. Flight trajectory of the TTL3 balloon during the Stratéole 2 engineering test. The trajectory represents $101 \mathrm{~d}$ of flight, each point is the position of a $2 \mathrm{~km}$ RACHuTS profile. Locations of the profiles in Figs. 5, 6, and 8 are marked. Base map courtesy of NASA Visible Earth.

in the torque, and therefore the current, in the main motor and level wind motors. These diagnostics showed no significant change in reel system performance while in flight, and there was no evidence that the reel system would degrade under the planned sampling regime of four profiles per night over $90 \mathrm{~d}$.

Motor torque can also provide insight into lift generated by the profiler line under high wind shear conditions, where reel motor torque below nominal levels would correspond to profiles exhibiting decreased gravitational loads. During the engineering flight, we did not observe decreased torque during any of the profiles, and while we do not have a direct measurement of wind speed from the profiler, the horizontal offset of the profiler relative to the Zephyr provides a proxy for the integrated wind shear over the length of the profile. Comparing motor torques for profiles with horizontal displacements $<200 \mathrm{~m}$ with profiles with horizontal displacements $>1000 \mathrm{~m}$ indicates that the impact on the reel system is not statistically significant with a $1 \sigma$ variability in motor torque of $4.7 \%$ (Fig. 5). It should also be noted that the CNES flight team did not observe significant changes in the TTL3 flight level during an active RACHuTS profile, further demonstrating that wind-shear-induced lift is not a concern for future Stratéole 2 missions.

Two significant anomalies were observed: the previously mentioned damage to the docking connector and anomalous sensor readings causing the reel to default to a safe mode. The damage to the docking connector led to intermittent failures in the docking procedure after profiles, which necessitated manual intervention from the ground station to rectify and often required several days for recovery. Intermittent, but persistent, erratic sensor readings in the reel control system caused the reel to enter a safe mode, again requiring intervention from the ground to rectify. The operational impact of these two anomalies was the inability to use the automatic mode and a significant reduction $(\sim 75 \%)$ in the total number of profiles collected relative to the operational plan.
The issues with the damage and intermittent communication through the profiler docking connector and erratic sensor readings are being addressed for future deployments. The connector has been redesigned to use more robust spring pins, and an additional fixture has been added to the spring pins to provide enhanced mechanical support. A long-range (LoRa) radio link will be added between the profiler and the PIB to provide continuous communications with the profiler, independent of the mechanical docking. In addition to redundant docked communications, the LoRa link also provides continuous communications during a profile, decreasing the latency of downlinking profile data. The temperature sensing system in the reel system and profiler have been revised to use digital temperature sensors to reduce erroneous readings, and the firmware has been modified to prevent erroneous readings from triggering safety interlocks.

\subsection{TSEN performance}

The performance of the sensors in the profiling unit is assessed based on two criteria: the technical operation of the sensor and, where possible, a comparison of the scientific measurement with independent measurements. The profiler TSEN operated nominally throughout the flight, both during profiles and while docked. TSEN collected 3.1 million measurements of pressure and temperature while docked and 300000 measurements during profiles. No anomalies were identified in the instrument operation, and missing data from the flight are due to communications issues with the profiler rather than to the TSEN instrument.

The measurement performance of TSEN is well characterized from prior long-duration flights. Two comparisons have been identified for the RACHuTS TSEN: comparison with the TSEN located on the Euros gondola for flight level data and comparisons with nearby radio soundings for profile data. Both comparisons have limitations. The positioning of the TSEN temperature sensor on the Euros gondola was dictated by logistical constraints and was not optimal for tem- 

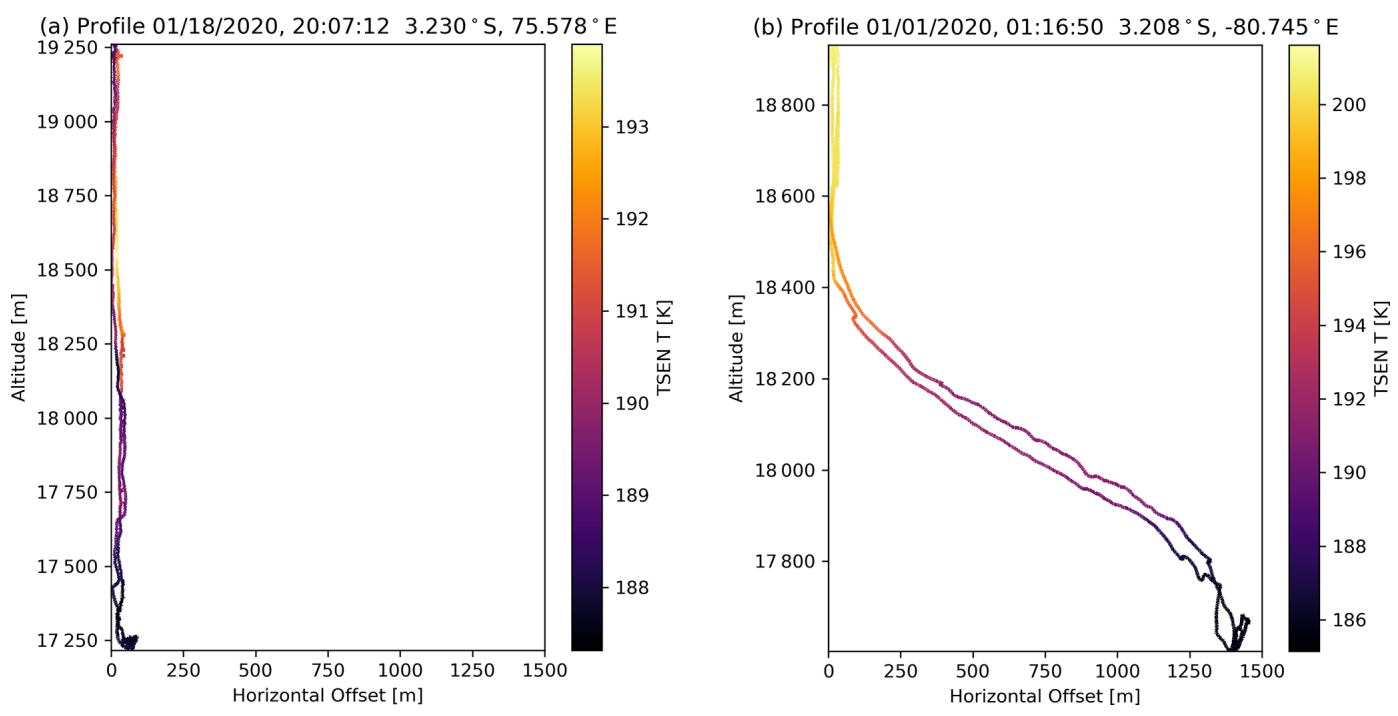

Figure 5. Horizontal offset of the profiling unit relative to the Zephyr gondola as a function of GPS altitude, color-coded by ambient temperature. (a) A low wind shear example demonstrating $<100 \mathrm{~m}$ horizontal displacement and a nearly isothermal profile. (b) High wind shear example with $1400 \mathrm{~m}$ horizontal displacement and $14 \mathrm{~K}$ temperature gradient. The difference in motor torque between these profiles is $4.7 \%$.

perature measurements. The sensor was approximately $1 \mathrm{~m}$ above the gondola. This resulted in significant contamination due to solar heating of the Euros gondola re-radiating to the temperature sensor. For all docked data points the RACHuTS TSEN had a mean offset of $-0.69 \mathrm{~K}$ relative to the Euros TSEN. When considering only the nighttime measurements, $\left(\mathrm{SZA}>95^{\circ}\right)$ the relative bias drops to $-0.46 \mathrm{~K}$. The pressure sensor used in the RACHuTS TSEN had a $3.84 \mathrm{hPa}$ mean positive bias relative to the high-accuracy Quartz barometer on the Euros TSEN after applying the manufacturer's supplied calibration to the docked TSEN data. The RACHuTS TSEN pressure sensor was operated outside the specified ambient temperature and pressure range to obtain optimum accuracy, leading to a decrease in absolute accuracy. The offset of the RACHuTS TSEN pressure measurement is a strong function of the temperature of the pressure sensor module. After applying an empirical linear correction to the pressure sensor as a function of the temperature of the sensing element and accounting for the $7 \mathrm{~m}$ vertical separation between the sensors, the mean offset between the two pressure sensors was reduced to $0.08 \mathrm{hPa}$ with a $1 \sigma$ variance of $0.55 \mathrm{hPa}$. This correction was then applied to all the RACHuTS TSEN pressure measurements.

Comparisons between RACHuTS profiles and radiosondes were rare due to the scarcity of radiosonde sites within the tropics. Fortuitously, two RACHuTS profiles over Brazil were within $300 \mathrm{~km}$ of three operational radiosonde sounding sites (Fig. 6). The profile collected on 3 January 2020 (Fig. 6b) was within $300 \mathrm{~km}$ of two radiosonde soundings; however there was significant horizontal and temporal variability in the TTL as is evident in the difference between the RACHuTS descent and ascent profiles, which were spaced
$76 \mathrm{~km}$ apart, and subsequent radiosonde soundings. Yet the RACHuTS profile is bracketed by the radiosonde profiles. A comparison from the day prior (Fig. 6b) shows significantly less spatial and temporal variability, with both the descent and ascent profiles as well as three soundings all agreeing within $3 \mathrm{~K}$. The RACHuTS profile shows significantly more detail than is available from the sounding, but the position of the cold-point tropopause (CPT) agrees within $50 \mathrm{~m}$, as well as a second inflection at $18.6 \mathrm{~km}$.

\subsection{FLASH-B performance}

The technical performance of FLASH-B throughout the flight was highly stable and within specification. The instrument was located outside the primary thermal housing and performed its own thermal control, with the lamp temperature reaching the nominal operation range within the $15 \mathrm{~min}$ pre-flight warmup period. The voltage and current supply to the hydrogen lamp were stable throughout the flight, indicative of highly stable Lyman-alpha emission, which is critical to the measurement. As was expected, the initial measurements from FLASH-B showed anomalously high water vapor in the vicinity of the balloon (within several hundred meters) (Fig. 7). This water vapor contamination is due to water vapor outgassing from the balloon and gondola surfaces and is unsurprising given the low-ventilation environment (Ghysels et al., 2016; Zander, 1966). The TTL3 balloon was launched into heavy cloud cover and it is suspected that the balloon was coated in ice during ascent. A coincident launch of the NOAA frost-point hygrometer (FPH) measured a total column water vapor of $52 \mathrm{~mm}$ and measured a deep, saturated layer in the upper troposphere, which likely exacer- 

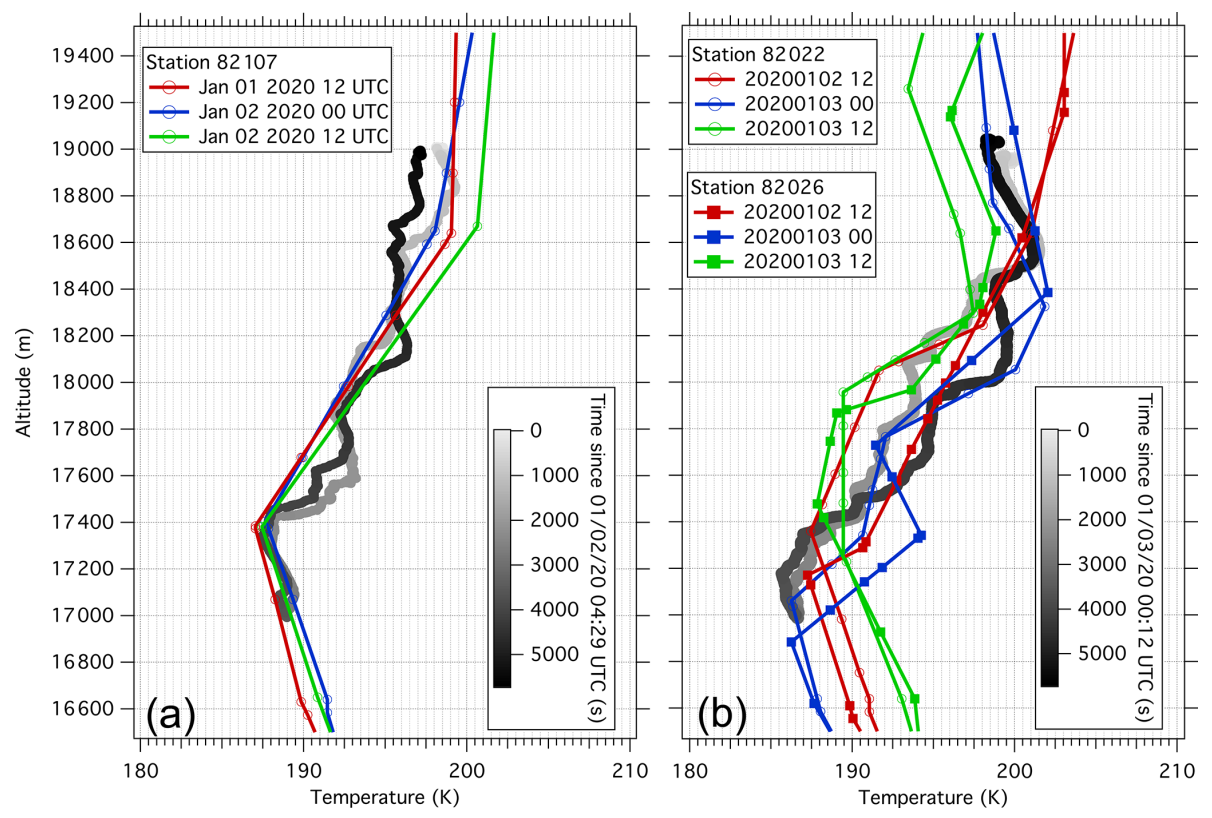

Figure 6. Comparison between RACHuTS temperature profiles and radiosonde soundings as a function of geometric (GPS) altitude. (a) RACHuTS profile collected at 04:50 on 1 January $2020(1.08,-68.75)$ and the three closest in time radiosonde soundings from São Gabriel da Cachoeira, Brazil (-0.12, -66.97, $239 \mathrm{~km}$ from profile). (b) RACHuTS profile collected at 00:12 on 3 January 2020 (2.10, -58.66) and the three closest in time radiosonde soundings from Boa Vista, Brazil $(2.83,-60.70,240 \mathrm{~km}$ from profile) and Tirios, Brazil (2.22, -55.95 , $302 \mathrm{~km}$ from profile).

bated the expected water vapor contamination. However, the water vapor contamination was largely limited to measurements early in the flight and to pressures below $67 \mathrm{hPa}$. During deployments, the profiler is ventilated by its own vertical motion as well as by wind shear encountered below the balloon. The measurements during the ascent of the profiler are more affected by outgassing as the downward-looking optics of FLASH-B sense the air coming down from the instrument surfaces.

The scientific performance of FLASH-B can be assessed through comparison with collocated Microwave Limb Sounder (MLS) measurements. Figure 7 shows a comparison of the relative frequency of FLASH-B water mixing ratio measurements during the descent phase of the profile to the mean water vapor mixing ratio derived from MLS profiles within $300 \mathrm{~km}$ and $24 \mathrm{~h}$ of the RACHuTS profiles. More than $90 \%$ of the FLASH-B measurements lie within the $1 \sigma$ variability of the MLS profiles, in spite of the limited vertical resolution of the MLS water vapor retrievals. Evidence of water vapor contamination from the balloon and gondola is present at pressures less than $67 \mathrm{hPa}$ and potential temperatures greater than $425 \mathrm{~K}$.

\subsection{ROPC performance}

ROPC operated nominally throughout all the profiles, collecting approximately 300000 measurements during the warmup, profile, and dwell periods. The only technical is-

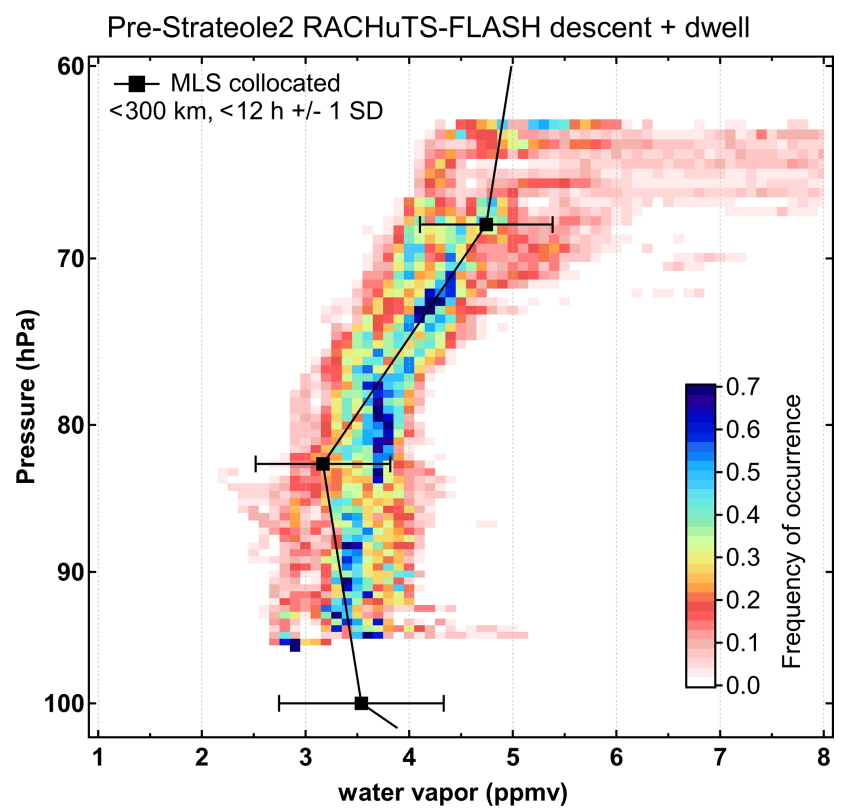

Figure 7. Comparison of the frequency of FLASH-B water vapor measurements from the 44 descent profiles with the average of the closest Microwave Limb Sounder water vapor measurements within $12 \mathrm{~h}$ of each profile. The positive bias of FLASH-B at pressures below $67 \mathrm{hPa}$ is attributed to outgassing of water vapor from the balloon and gondola. 

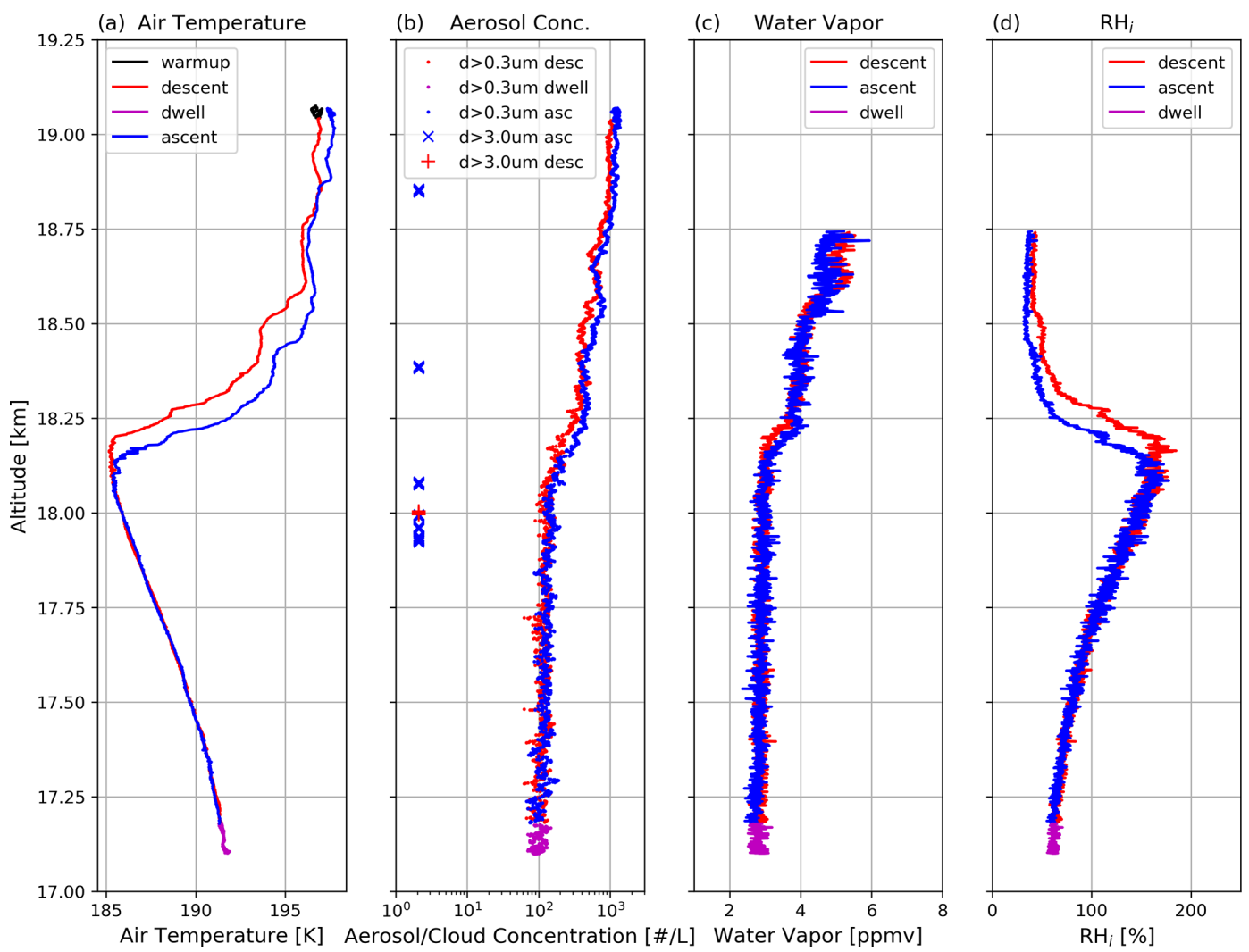

Figure 8. RACHuTS profile measurement collected in the eastern Pacific. All plots are a function of GPS altitude (left to right). (a) TSEN air temperature; note the clear cold point $(185 \mathrm{~K})$ at $18.2 \mathrm{~km}$ and wave-driven temperature structures near 18.4 and $18.9 \mathrm{~km}$ on ascent. (b) ROPC aerosol or cloud concentration; note the presence of large particles $(d>3.0 \mu \mathrm{m})$, likely cirrus cloud ice particles, near the cold point $(18.2 \mathrm{~km})$ associated with negative temperature anomalies at 18.4 and $18.9 \mathrm{~km}$. (c) FLASH-B water vapor mixing ratio; note the relatively constant mixing ratio across the cold point $(18.2 \mathrm{~km})$. (d) Calculated relative humidity over ice; near the cold-point supersaturations exceed $150 \%$ suggesting minimal dehydration through cloud formation.

sue related to ROPC was an occasional erroneous temperature reading from the thermistor on the rotary vane pump that required correction in post-processing.

Independent in-flight validation of the ROPC is difficult to achieve as satellites cannot retrieve aerosol size distributions and balloon-borne aerosol soundings are not routinely performed in the tropics. However, the LPC instrument (flow rate $\sim 20 \mathrm{~L} \mathrm{~m}^{-1}$ ) was also hosted on the same gondola as RACHuTS and measured particle size distributions from $0.3-24 \mu \mathrm{m}$ in 32 channels every hour at the balloon flight level. LPC provides an in situ comparison for the ROPC while it is docked at flight level in the warmup preceding each profile. Six measurement periods were identified when both LPC and ROPC were operating nominally and made measurements within $15 \mathrm{~min}$ of each other. The size distributions from LPC were re-binned to match the channels from ROPC and the concentrations for each ROPC channels were compared. The total ROPC concentration (all particles $>0.3 \mu \mathrm{m}$ ) was on average 0.54 of the concentration of particles $>0.3 \mu \mathrm{m}$ from LPC. The $1.0 \mu \mathrm{m}$ channel was the largest ROPC channel to routinely detect particles at float altitude and was 0.25 the concentration of the LPC $1.0 \mu \mathrm{m}$ channel. If the LPC size distributions are re-binned at sizes $\sim 20 \%$ larger than the ROPC nominal channels, ROPC is 0.85 times LPC for the $0.3 \mu \mathrm{m}$ channel and 1.05 times for the $1.0 \mu \mathrm{m}$ channel, well within the ROPC uncertainty. This suggests that ROPC is slightly undersizing particles relative to the LPC.

\section{Example of the scientific measurements}

As mentioned above, in spite of the engineering difficulties encountered the profiler completed 55 descent and ascent profiles beneath the Zephyr, which maintained an altitude near $19 \mathrm{~km}$ throughout the flight. The location of these profiles, which span the central Pacific to Indian oceans, are shown in Fig. 4. An example profile collected in the eastern Pacific illustrates several features of scientific interest and relevant to the scientific mission. Figure 8 displays the temperature, aerosol or cloud, water vapor, and ice supersaturation which were measured on this profile. The RACHuTS profiler descends to $\sim 800 \mathrm{~m}$ below the CPT; Fig. $8 \mathrm{a}$. The 
descent and ascent each require $30 \mathrm{~min}$ and the dwell at the bottom lasted $15 \mathrm{~min}$. In that time the profiler moved $37 \mathrm{~km}$ to the northeast. The temperature of the upper troposphere is very homogeneous throughout this area, and the temperature offset above the tropopause is consistent with the isentropic gradient between the ascent and descent profiles. Above the CPT, two temperature perturbations are evident in the ascent profile at 18.4 and $18.9 \mathrm{~km}$. Collocated with the cold phase of these wave-driven temperature perturbations there is an enhancement of large $(d>3 \mu \mathrm{m})$ particles (Fig. $8 \mathrm{~b})$, most likely cirrus cloud ice particles, confirming the wave-driven cirrus cloud formation observations obtained during ATTREX (Kim et al., 2016). Further cirrus cloud ice particles are observed near the CPT on both descent and ascent, suggesting the presence of a sub-visible cirrus cloud near the CPT with significant horizontal extent. Surprisingly, water vapor mixing ratios are essentially constant across the CPT (Fig. 8c); instead significant supersaturations with respect to ice are observed (Fig. 8d). A detailed analysis of the scientific results from the campaign will be presented in forthcoming publications.

\section{Summary}

The successful deployment of the RACHuTS instrument on Stratéole 2 engineering test campaign in 2019-2020 demonstrates the value of profiling instruments for use on longduration balloons. In spite of the campaign being focused on engineering data and testing, the RACHuTS instrument produced an unprecedented number (110) of vertical profiles of water vapor, temperature, and clouds or aerosol through the TTL. These research quality measurements not only validate the instrument concept but also directly address the science questions that motivated the design of the instrument.

The technical issues observed in the RACHuTS instrument during the campaign have been addressed with minor design revisions that will be implemented prior to the first Stratéole 2 science campaign in 2021. Three more RACHuTS instruments are in production for launch in 2021, and a further three instruments are planned for the second science campaign in 2024.

Code availability. The instrument operating code was developed by the authors and is publicly available at https://doi.org/10.5281/zenodo.4645916 (St. Clair, 2021).

Data availability. At the time of publication, the Stratéole 2 data set is still under a 1-year embargo and not yet publicly available. Future publications from this campaign will include a link to the data set.
Author contributions. LEK led the instrument design, assembly, and test and wrote the paper. AH and JB provided the TSEN sensor. AL and SK provided the FLASH-B sensor. JDG assisted in instrument design and assembly and led the laboratory testing of the instrument. SMD, LEK, and TD conceptualized the instrument and analyzed instrument data. ASC developed the instrument firmware and assisted with assembly and the test. LEK, TD, JDG, SMD, SK, ASC, AH, and JB participated in the field campaign. AH is scientific lead of the Stratéole 2 project.

Competing interests. The authors declare that they have no conflict of interest.

Acknowledgements. The authors gratefully acknowledge the support of the Stratéole 2 science teams, the LATMOS/LMD gondola engineering team, the CNES balloon team, and the Seychelles Meteorological Agency. This work was funded by the NSF under award 1643022, with kind support provided by CNES and CNRS. Special thanks to Philippe Cocquerez and Stephanie Venel for making the flight of this unorthodox instrument possible on a CNES balloon.

Financial support. This research has been supported by the National Science Foundation, Directorate for Geosciences (grant no. 1643022).

Review statement. This paper was edited by Alyn Lambert and reviewed by Masatomo Fujiwara and one anonymous referee.

\section{References}

Alexander, K. and Stevenson, J.: Kite equilibrium and bridle length, Aeronaut. J., 105, 535-541, https://doi.org/10.1017/S0001924000017991, 2001.

Baldwin, M. P., Gray, L. J., Dunkerton, T. J., Hamilton, K., Haynes, P. H., Randel, W. J., Holton, J. R., Alexander, M. J., Hirota, I., Horinouchi, T., Jones, D. B. A., Kinnersley, J. S., Marquardt, C., Sato, K., and Takahashi, M.: The quasi-biennial oscillation, Rev. Geophys., 39, 179-229, https://doi.org/10.1029/1999RG000073, 2001.

Boullot, N., Rabier, F., Langland, R., Gelaro, R., Cardinali, C., Guidard, V., Bauer, P., and Doerenbecher, A.: Observation impact over the southern polar area during the Concordiasi field campaign, Q. J. Roy. Meteor. Soc., 142, 597-610, https://doi.org/10.1002/qj.2470, 2016.

Campbell, P. and Deshler, T.: Condensation nuclei measurements in the midlatitude (1982-2012) and Antarctic (1986-2010) stratosphere between 20 and 35 km, J. Geophys. Res.-Atmos., 119, 137-152, https://doi.org/10.1002/2013JD019710, 2013.

Fahey, D. W., Gao, R.-S., Möhler, O., Saathoff, H., Schiller, C., Ebert, V., Krämer, M., Peter, T., Amarouche, N., Avallone, L. M., Bauer, R., Bozóki, Z., Christensen, L. E., Davis, S. M., Durry, G., Dyroff, C., Herman, R. L., Hunsmann, S., Khaykin, S. M., Mackrodt, P., Meyer, J., Smith, J. B., Spelten, N., Troy, R. F., Vömel, 
H., Wagner, S., and Wienhold, F. G.: The AquaVIT-1 intercomparison of atmospheric water vapor measurement techniques, Atmos. Meas. Tech., 7, 3177-3213, https://doi.org/10.5194/amt-73177-2014, 2014.

Fueglistaler, S., Dessler, A. E., Dunkerton, T. J., Folkins, I., Fu, Q., and Mote, P. W.: Tropical tropopause layer, Rev. Geophys., 47, RG1004, https://doi.org/10.1029/2008RG000267, 2009.

Fujiwara, M., Vömel, H., Hasebe, F., Shiotani, M., Ogino, S.Y., Iwasaki, S., Nishi, N., Shibata, T., Shimizu, K., Nishimoto, E., Valverde-Canossa, J. M., Selkirk, H. B., and Oltmans, S. J.: Seasonal to decadal variations of water vapor in the tropical lower stratosphere observed with balloon-borne cryogenic frostpoint hygrometers, J. Geophys. Res., 115, D18304, https://doi.org/10.1029/2010JD014179, 2010.

Ghysels, M., Riviere, E. D., Khaykin, S., Stoeffler, C., Amarouche, N., Pommereau, J.-P., Held, G., and Durry, G.: Intercomparison of in situ water vapor balloon-borne measurements from PicoSDLA H2O and FLASH-B in the tropical UTLS, Atmos. Meas. Tech., 9, 1207-1219, https://doi.org/10.5194/amt-9-1207-2016, 2016.

Haase, J., Alexander, M., Hertzog, A., Kalnajs, L., Deshler, T., Davis, S., Plougonven, R., Cocquerez, P., and Venel, S.: Around the world in 84 days, EOS T. Am. Geophys. Un., 99, https://doi.org/10.1029/2018EO091907, 2018.

Hasebe, F., Inai, Y., Shiotani, M., Fujiwara, M., Vömel, H., Nishi, N., Ogino, S.-Y., Shibata, T., Iwasaki, S., Komala, N., Peter, T., and Oltmans, S. J.: Cold trap dehydration in the Tropical Tropopause Layer characterised by SOWER chilledmirror hygrometer network data in the Tropical Pacific, Atmos. Chem. Phys., 13, 4393-4411, https://doi.org/10.5194/acp13-4393-2013, 2013.

Hazen, N. L. and Anderson, J. G.: A new reeling technique for very long extension scanning in the stratosphere, Adv. Space Res., 5, 45-48, https://doi.org/10.1016/0273-1177(85)90422-3, 1985.

Hertzog, A., Basdevant, C., Vial, F. and Mechoso, C. R.: The accuracy of stratospheric analyses in the northern hemisphere inferred from long-duration balloon flights, Q. J. Roy. Meteor. Soc., 130, 607-626, https://doi.org/10.1256/qj.03.76, 2004.

Hertzog, A., Cocquerez, P., Guilbon, R., Valdivia, J.-N., Venel, S., Basdevant, C., Boccara, G., Bordereau, J., Brioit, B., Vial, F., Cardonne, A., Ravissot, A. and Schmitt, É.: Stratéole/Vorcore-Long-duration, Superpressure Balloons to Study the Antarctic Lower Stratosphere during the 2005 Winter, J. Atmos. Ocean. Tech., 24, 2048-2061, https://doi.org/10.1175/2007JTECHA948.1, 2007.

Hoffmann, L., Hertzog, A., Rößler, T., Stein, O., and Wu, X.: Intercomparison of meteorological analyses and trajectories in the Antarctic lower stratosphere with Concordiasi superpressure balloon observations, Atmos. Chem. Phys., 17, 8045-8061, https://doi.org/10.5194/acp-17-8045-2017, 2017.

International Civil Aviation Organisation (ICAO): Rules of the Air, 10th Edn., Annex 2 to the Convention on International Civil Aviation, ICAO, Canada, 2005.

Jensen, E. J., Pfister, L., Jordan, D. E., Bui, T. V., Ueyama, R., Singh, H. B., Thornberry, T. D., Rollins, A. W., Gao, R.-S., Fahey, D. W., Rosenlof, K. H., Elkins, J. W., Diskin, G. S., DiGangi, J. P., Lawson, R. P., Woods, S., Atlas, E. L., Navarro Rodriguez, M. A., Wofsy, S. C., Pittman, J., Bardeen, C. G., Toon, O. B., Kindel, B. C., Newman, P. A., McGill, M. J.,
Hlavka, D. L., Lait, L. R., Schoeberl, M. R., Bergman, J. W., Selkirk, H. B., Alexander, M. J., Kim, J.-E., Lim, B. H., Stutz, J., and Pfeilsticker, K.: The NASA Airborne Tropical Tropopause Experiment: High-Altitude Aircraft Measurements in the Tropical Western Pacific, B. Am. Meteorol. Soc., 98, 129-143, https://doi.org/10.1175/BAMS-D-14-00263.1, 2015.

Khaykin, S., Pommereau, J.-P., Korshunov, L., Yushkov, V., Nielsen, J., Larsen, N., Christensen, T., Garnier, A., Lukyanov, A., and Williams, E.: Hydration of the lower stratosphere by ice crystal geysers over land convective systems, Atmos. Chem. Phys., 9, 2275-2287, https://doi.org/10.5194/acp-9-2275-2009, 2009.

Khaykin, S. M., Engel, I., Vömel, H., Formanyuk, I. M., Kivi, R., Korshunov, L. I., Krämer, M., Lykov, A. D., Meier, S., Naebert, T., Pitts, M. C., Santee, M. L., Spelten, N., Wienhold, F. G., Yushkov, V. A., and Peter, T.: Arctic stratospheric dehydration - Part 1: Unprecedented observation of vertical redistribution of water, Atmos. Chem. Phys., 13, 11503-11517, https://doi.org/10.5194/acp-13-11503-2013, 2013.

Kim, J.-E., Alexander, M. J., Bui, T. P., Dean-Day, J. M., Lawson, R. P., Woods, S., Hlavka, D., Pfister, L., and Jensen, E. J.: Ubiquitous influence of waves on tropical high cirrus clouds, Geophys. Res. Lett., 43, 5895-5901, https://doi.org/10.1002/2016GL069293, 2016.

Krämer, M., Rolf, C., Spelten, N., Afchine, A., Fahey, D., Jensen, E., Khaykin, S., Kuhn, T., Lawson, P., Lykov, A., Pan, L. L., Riese, M., Rollins, A., Stroh, F., Thornberry, T., Wolf, V., Woods, S., Spichtinger, P., Quaas, J., and Sourdeval, O.: A microphysics guide to cirrus - Part 2: Climatologies of clouds and humidity from observations, Atmos. Chem. Phys., 20, 12569-12608, https://doi.org/10.5194/acp-20-12569-2020, 2020.

Lykov, A., Khaykin, S., Yushkov, V., Efremov, D., Formanyuk, I., and Astakhov, V.: Fluorescence Lyman-Alpha Stratospheric Hygrometer (FLASH): application on meteorological balloons, long duration balloons and unmanned aerial vehicles, 40th COSPAR Scientific Assembly, 2-10 August 2014 Moscow, Russia PSB.123-14, 2014.

Matsuzaka, Y., Yamagami, T., Yamanaka, M. D., and Nishimura, J.: Development of balloon-borne reel-down and -up winch system, Adv. Space Res., 5, 41-44, https://doi.org/10.1016/02731177(85)90421-1, 1985.

Petzl, M., Kasper, M., and Danzer, M. A.: Lithium plating in a commercial lithium-ion battery - A lowtemperature aging study, J. Power Sources, 275, 799-807, https://doi.org/10.1016/j.jpowsour.2014.11.065, 2015.

Podglajen, A., Hertzog, A., Plougonven, R., and Žagar, N.: Assessment of the accuracy of (re)analyses in the equatorial lower stratosphere, J. Geophys. Res.-Atmos., 119, 11166-11188, https://doi.org/10.1002/2014JD021849, 2014.

Rabier, F., Cohn, S., Cocquerez, P., Hertzog, A., Avallone, L., Deshler, T., Haase, J., Hock, T., Doerenbecher, A., Wang, J., Guidard, V., Thépaut, J.-N., Langland, R., Tangborn, A., Balsamo, G., Brun, E., Parsons, D., Bordereau, J., Cardinali, C., Danis, F., Escarnot, J.-P., Fourrié, N., Gelaro, R., Genthon, C., Ide, K., Kalnajs, L., Martin, C., Meunier, L.-F., Nicot, J.-M., Perttula, T., Potts, N., Ragazzo, P., Richardson, D., Sosa-Sesma, S., and Vargas, A.: The Concordiasi Field Experiment over Antarctica: First Results from Innovative Atmospheric Measurements, B. Am. 
Meteorol. Soc., 94, ES17-ES20, https://doi.org/10.1175/BAMSD-12-00005.1, 2012.

Randel, W. J. and Jensen, E. J.: Physical processes in the tropical tropopause layer and their roles in a changing climate, Nat. Geosci., 6, 169-176, https://doi.org/10.1038/ngeo1733, 2013.

Rosen, J. M. and Hofmann, D. J.: Balloonborne Measurements of Condensation Nuclei, J. Appl. Meteorol., $\quad 16, \quad 56-62, \quad$ https://doi.org/10.1175/15200450(1977)016<0056:BMOCN>2.0.CO;2, 1977.

Selkirk, H. B., Vömel, H., Canossa, J. M. V., Pfister, L., Diaz, J. A., Fernández, W., Amador, J., Stolz, W., and Peng, G. S.: Detailed structure of the tropical upper troposphere and lower stratosphere as revealed by balloon sonde observations of water vapor, ozone, temperature, and winds during the NASA TCSP and TC4 campaigns, J. Geophys. Res.-Atmos., 115, D00J19, https://doi.org/10.1029/2009JD013209, 2010.

Sobieraj, M. and Rimnac, C.: Ultra High Molecular Weight Polyethylene: Mechanics, Morphology, and Clinical Behavior, J. Mech. Behav. Biomed. Mater., 2, 433-443, https://doi.org/10.1016/j.jmbbm.2008.12.006, 2009.

St. Clair, A.: StratoCore V2.0, Zenodo [code], https://doi.org/10.5281/zenodo.4645916, 2021.
Suzuki, J., Fujiwara, M., Nishizawa, T., Shirooka, R., Yoneyama, K., Katsumata, M., Matsui, I., and Sugimoto, N.: The occurrence of cirrus clouds associated with eastward propagating equatorial inertio-gravity and Kelvin waves in November 2011 during the CINDY2011/DYNAMO campaign, J. Geophys. Res., 118, 12941-12947, https://doi.org/10.1002/2013JD019960, 2013.

Vömel, H., Yushkov, V., Khaykin, S., Korshunov, L., Kyrö, E., and Kivi, R.: Intercomparisons of Stratospheric Water Vapor Sensors: FLASH-B and NOAA/CMDL FrostPoint Hygrometer, J. Atmos. Ocean. Tech., 24, 941-952, https://doi.org/10.1175/JTECH2007.1, 2007.

Ward, S. M., Deshler, T., and Hertzog, A.: Quasi-Lagrangian measurements of nitric acid trihydrate formation over Antarctica, J. Geophys. Res.-Atmos., 119, 245-258, https://doi.org/10.1002/2013JD020326, 2014.

Yushkov, V., Astakhov, V. and Merkulov, S.: Optical balloon hygrometer for upper-troposphere and stratosphere water vapor measurements, P. Soc. Photo.-Opt. Ins., 3501, 439-445, 1998.

Zander, R.: Moisture contamination at altitude by balloon and associated equipment, J. Geophys. Res., 71, 3775-3778, https://doi.org/10.1029/JZ071i015p03775, 1966. 